\title{
$\mathrm{WLAN}$ 대역 저지 특성을 가지는 직렬 급전 다이폴 쌍 안테나 \\ 여준호 ${ }^{1}$, 홍재표 $^{2}$, 이종익 $3^{*}$ \\ ${ }^{1}$ 대구대학교 정보통신공학부, ${ }^{2}$ 경일대학교 전자공학과, ${ }^{3}$ 동서대학교 전자공학과
}

\section{Series-Fed Dipole Pair Antenna with WLAN Band Rejection Characteristic}

\author{
Junho Yeo ${ }^{1}$, Jae Pyo Hong ${ }^{2}$ and Jong-Ig Lee (3* $^{3^{*}}$ \\ ${ }^{1}$ School of Computer and Communication Engineering, Daegu University \\ ${ }^{2}$ Department of Electronics Engineering, Kyungil University \\ ${ }^{3}$ Department of Electronics Engineering, Dongseo University
}

\begin{abstract}
요 약 본 논문에서는 $1.7-2.7 \mathrm{GHz}$ 대역에서 동작하는 이동통신 기지국용 광대역 직렬 급전 다이폴 쌍 (SDP) 안테 나에 대하여 2.4-2.484 GHz 무선랜(WLAN) 대역에서 저지 특성을 가지기 위한 설계 방법을 연구하였다. 대역 저지 특성은 SDP 안테나의 두 다이폴 소자를 연결하는 코플래너 스트립 선로 상에 U자형 슬롯을 삽입함으로써 얻을 수 있다. 슬롯의 위치와 구조에 따른 저지 대역의 특성 변화를 분석하였다. 최적화된 WLAN 대역 저지 SDP 안테나를 FR4 기판 상에 제작하고 특성을 실험한 결과 VSWR < 2 인 대역은 $1.65-2.78 \mathrm{GHz}(51.0 \%)$ 이고, 저지 대역은 2.39 $-2.54 \mathrm{GHz}$ 로 원하는 대역 저지 성능을 갖는 것을 확인하였다.
\end{abstract}

\begin{abstract}
In this paper, a design method to obtain a band rejection characteristic in the $2.4-2.484 \mathrm{GHz}$ WLAN band is studied for a series-fed dipole pair (SDP) antenna operating in the band of 1.7-2.7 $\mathrm{GHz}$ for mobile communication base station applications. The band rejection characteristic is achieved by inserting U-shaped slots on the coplanar strip line connecting the two dipole elements of the SDP antenna. The effects of the location and dimension of the slots on the rejection band characteristics are examined. The optimized SDP antenna with WLAN band rejection is fabricated on an FR4 substrate and the experimental results show that the antenna has a desired band rejection performance with a frequency band of $1.65-2.78 \mathrm{GHz}(51.0 \%)$ for a VSWR $<2$, and a rejection band of $2.39-2.54 \mathrm{GHz}$.
\end{abstract}

Key Words : Bnd rejection, Broadband antenna, Mobile communication, Series-fed dipole pair antenna

\section{1. 서론}

최근 무선통신의 급속한 발달로 인해 가볍고 저가이며 인쇄기판을 이용하여 제작이 용이한 광대역 프린트 안테 나에 대한 요구가 증가하고 있다[1]. 대역폭을 증가시키 기 위해 집적형 밸런 (integrated balun)을 사용한 프린트 된 다이폴 안테나, 평면 직렬 급전 다이폴 쌍(series-fed dipole pair; SDP) 안테나, 평면 준-야기(quasi-Yagi; QY)
안테나 등과 같이 프린트된 다이폴 안테나를 변형한 여 러 방법이 시도되었다[2-5]. 특히, SDP 안테나는 넓은 대 역, 안정된 이득과 간단한 구조로 인해 기지국 안테나와 광대역 위상 배열 안테나 등과 같은 여러 이동통신 응용 분야에 많이 사용되어 왔다 $[3,4]$

$\mathrm{SDP}$ 안테나는 두 개의 길이가 다른 다이폴과 절단된 접지면으로 구성되며, 이들 소자들이 전송선로를 통해 직 렬로 연결되어 있다[3]. 일반적으로, 두 다이폴의 길이는

본 논문은 2009년도 경일대학교 교내 일반 연구비를 지원 받았음.

"Corresponding Author : Jong-Ig Lee(Dongseo Univ.)

Tel: +82-51-320-1761 email: leeji@dongseo.ac.kr

Received March 4, $2013 \quad$ Revised March 12, 2013

Accepted April 11, 2013 
동작 주파수 대역내에서 각각 낮은 공진 주파수와 높은 공진 주파수를 제어할 수 있으며, 두 다이폴 사이의 간격 과 첫 번째 다이폴과 접지면 사이의 간격은 두 공진주파 수 사이의 입력 임피던스를 조절하여 반사계수 레벨을 제어할 수 있다.

한편, 광대역 안테나를 사용할 경우 사용 주파수 대역 내에서 기존의 다른 무선 통신 서비스 신호들을 수신할 경우 상호 간섭 문제가 발생될 수 있으며, 이를 방지하기 위해서 안테나 자체의 구조를 변경하여 특정 대역을 저 지하는 설계 방법이 주로 사용되고 있다. 안테나 자체적 으로 특정 대역을 저지하기 위해서 사용되는 기술은 대 부분 방사체 내에 특정 주파수 대역 중심 주파수의 반파 장 길이를 가지는 슬롯을 삽입하거나 혹은 개방된 사분 파장의 슬롯을 삽입한다. 또한, 여러 대역에 대해서 저지 를 하기 위해서는 여러 개의 크기가 다른 슬롯을 삽입한 다[6-7]. 예를 들면, UWB 통신의 주파수 대역은 무선랜 (WLAN) 대역(2.4-2.484 GHz, 5.15-5.825 GHz)을 포함하 고 있으므로 전파 간섭 문제가 발생하게 된다. 이 문제를 해결하기 위하여, UWB 안테나의 방사체나 접지면에 CSRR(Complementary Split Ring Resonator) 형태의 슬롯 을 삽입하거나 급전선 근처에 SRR(Split Ring Resonator) 형태의 스터브(stub)를 추가하여 대역을 저지하였다[8-9]. 그러나 광대역 직렬 급전 다이폴 쌍 안테나에 대하여 2.4-2.484 GHz 무선랜 대역 저지 특성에 관한 연구는 보 고되지 않았다.

본 논문에서는 $1.7-2.7 \mathrm{GHz}$ 대역에서 동작하는 이동통 신 기지국용 광대역 직렬 급전 다이폴 쌍 (SDP) 안테나 에 대하여 2.4-2.484 GHz 무선랜 대역에서 저지 특성을 가지기 위한 설계 방법을 연구하였다. 먼저, 두 다이폴과 접지면의 길이와 간격을 최적화하여 $1.7-2.7 \mathrm{GHz}$ 대역에 서 동작하는 SDP 안테나를 설계하였다[10]. 급전부를 최 소화하기 위해 단락이 종단된 마이크로스트립(microstrip: $\mathrm{MS}$ ) 선로와 슬롯(slot) 선로로 구성된 집적형 밸런 (integrated balun)을 사용하였다. 2.4-2.484 GHz WLAN 대역에서 저지 특성을 얻기 위하여, SDP 안테나의 두 다 이폴 소자를 연결하는 코플래너 스트립(coplanar stripline: CPS) 선로 상에 U자형 슬롯을 삽입하여 슬롯의 위치와 구조에 따른 저지 대역의 특성 변화를 분석하였 다. 상용 툴인 CST사의 Microwave Studio (MWS)를 이 용하여 안테나의 특성을 시뮬레이션하고 설계 변수를 최 적화하였다.

\section{2. 안테나 구조 및 설계}

\section{1 안테나 구조}

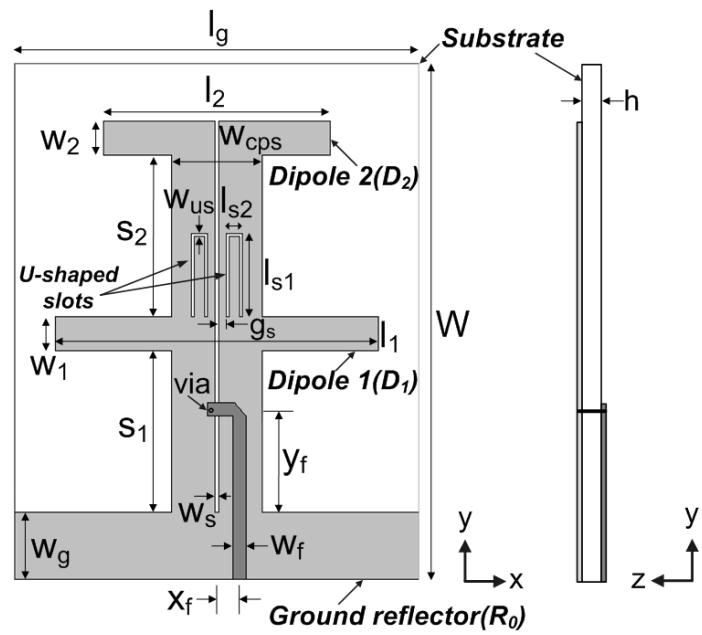

[Fig. 1] Geometry of proposed SDP antenna with WLAN band rejection characteristic.

제안된 WLAN 대역 저지특성을 가지는 $\mathrm{SDP}$ 안테나 의 구조는 Fig. 1 에 나타나 있다. 안테나가 인쇄된 기판의 전면에는 두 개의 길이가 다른 다이폴 안테나 $\left(D_{1}\right.$ 및 $\left.D_{2}\right)$, 반사기 역할을 하는 접지면 $\left(R_{0}\right)$, 그리고 이들을 연결하는 $\mathrm{CPS}$ 선로로 구성된다. 뒷면에는 MS선로가 있으며 끝부 분을 단락시키기 위해 비아(via)를 이용해 전면의 CPS의 한쪽과 연결된다. $\mathrm{MS}$ 의 길이 즉 급전점의 위치를 조정하 여 특성임피던스 50 옴( $(\Omega)$ 인 MS과 광대역 정합을 시킬 수 있다. 이 때 단락이 종단된 MS선로와 슬롯선로는 내 장형 밸런을 구성한다. Fig. 1에서 첫 번째 및 두 번째 다 이폴의 길이와 폭은 각각 $\mathrm{l}_{1}, \mathrm{w}_{1}, \mathrm{l}_{2}, \mathrm{w}_{2}$ 이고, 첫 번째 다이 폴과 반사기 사이의 간격과 두 다이폴 사이의 간격은 $\mathrm{s}_{1}$ 과 $\mathrm{s}_{2}$ 이다. 접지 면인 반사기의 길이와 폭은 각각 $\mathrm{lg}_{\mathrm{g}}$ 과 $\mathrm{wg}_{\mathrm{g}}$ 이다. 슬롯선로의 중심으로부터 $\mathrm{MS}$ 선로의 중심까지의 거리는 $\mathrm{xf}_{\mathrm{f}}$ 이고 반사기로부터 급전 점까지 $\mathrm{MS}$ 선로의 길이 는 $\mathrm{yf}_{\mathrm{f}}$ 이다. 1.7-2.7 GHz 대역에서 대역폭을 최대화하면서 이득 변화를 최소화시키기 위해 최적화된 설계 변수는 다음과 같다[10]. $\mathrm{lg}_{\mathrm{g}}=90 \mathrm{~mm}, \mathrm{wg}_{\mathrm{g}}=15 \mathrm{~mm}, \mathrm{~s}_{1}=\mathrm{s}_{2}=$ $36 \mathrm{~mm}, \mathrm{x}_{\mathrm{f}}=5 \mathrm{~mm}, \mathrm{y}_{\mathrm{f}}=23 \mathrm{~mm}, \mathrm{l}_{1}=72 \mathrm{~mm}, \mathrm{l}_{2}=50.4$ $\mathrm{mm}, \mathrm{w}_{1}=\mathrm{w}_{2}=7.5 \mathrm{~mm} . \mathrm{w}_{\mathrm{CPS}}=20 \mathrm{~mm}, \mathrm{w}_{\mathrm{s}}=0.7 \mathrm{~mm}$, $\mathrm{W}=115 \mathrm{~mm}, \mathrm{~h}=1.6 \mathrm{~mm}$.

2.4-2.484 GHz WLAN 대역에서 저지 특성을 생성하 기 위하여, Fig. 1에 나타난 바와 같이 SDP 안테나의 두 다이폴 소자를 연결하는 $\mathrm{CPS}$ 선로 상에 U자형 슬롯을 대칭되게 삽입하였다. 최적화된 U자형 슬롯의 설계 변수 는 다음과 같다. $1_{\mathrm{s} 1}=18 \mathrm{~mm}, \mathrm{l}_{\mathrm{s} 2}=3.5 \mathrm{~mm}, \mathrm{~g}_{\mathrm{s}}=1.8 \mathrm{~mm}$, $\mathrm{w}_{\mathrm{us}}=0.5 \mathrm{~mm}$. 여기서 $1_{\mathrm{s} 1}$ 은 $\mathrm{y}$ 축 방향 슬롯 길이, $\mathrm{1}_{\mathrm{s} 2}$ 는 $\mathrm{x}$ 축 
방향 슬롯 길이, $\mathrm{g}_{\mathrm{s}}$ 는 U자형 슬롯이 CPS 선로의 중심부 로부터의 떨어진 거리, $\mathrm{w}_{\mathrm{us}}$ 는 $\mathrm{U}$ 자형 슬롯의 폭이다.

\subsection{U자형 슬롯 설계}

$\mathrm{U}$ 자형 슬롯의 전체 길이는 대략 $2 \times l_{s 1}+l_{s 2}$ 이며 저지 대역 중심 주파수의 반 파장 길이에 근접하여야 한 다. 안테나가 프린트된 유전체의 유효 유전율을 고려하면 슬롯의 전체 길이와 저지 대역 중심 주파수 $\left(f_{c}\right)$ 와의 관계 는 식 (1)과 같이 표현 된다.

$$
f_{c} \approx \frac{c}{2\left(2 \times l_{s 1}+l_{s 2}\right) \sqrt{\epsilon_{e f f}}}
$$

여기서 $c$ 는 빛의 속도, $\epsilon_{e f f}$ 는 유전체의 유효 유전율 이다. 식 (1)에서 알 수 있듯이 저지 대역 중심 주파수를 조정할 수 있는 설계 변수는 슬롯의 길이인 $1_{\mathrm{s} 1}$ 과 $1_{\mathrm{s} 2}$ 임을 알 수 있다.

따라서, $\mathrm{y}$ 축 방향 슬롯 길이 $1_{\mathrm{s} 1}$ 와 $\mathrm{x}$ 축 방향 슬롯 길이 $1_{\mathrm{s} 2}$ 를 포함하여 CPS 선로의 중심부로 부터의 떨어진 거리 인 $\mathrm{g}_{\mathrm{s}}$ 와 슬롯의 폭 $\mathrm{w}_{\mathrm{us}}$ 에 대한 저지 대역 특성의 영항을 조사하였다.

Fig. 2는 y축 방향 슬롯 길이 $1_{s 1}$ 의 변화에 따른 입력 VSWR의 변화를 나타내고 있다. $\mathrm{y}$ 축 방향 슬롯 길이 $1_{\mathrm{s} 1}$ 가 증가할수록 저지 대역 주파수가 저주파 대역으로 이 동하고 저지 대역의 대역폭도 조금 증가함을 알 수 있다.

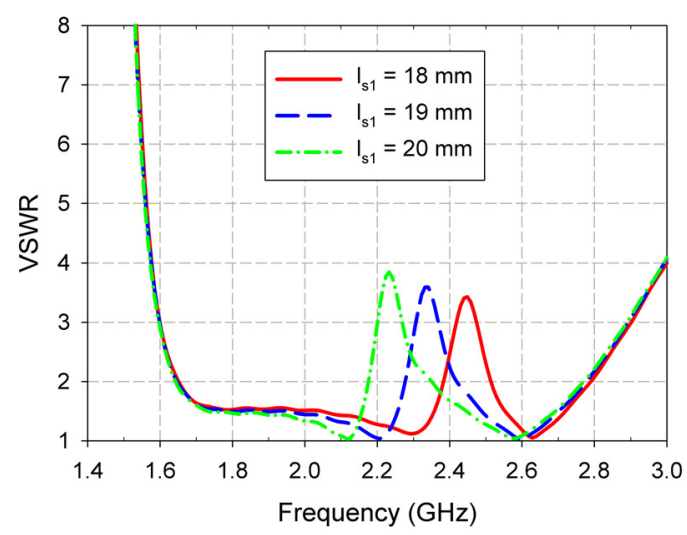

[Fig. 2] Input VSWR characteristic for varying slot length $1_{\mathrm{s} 1}$ in y-direction $\left(1_{\mathrm{s} 2}=3.5 \mathrm{~mm}, \mathrm{~g}_{\mathrm{s}}=1.8 \mathrm{~mm}\right.$, and $\left.\mathrm{W}_{\mathrm{us}}=0.5 \mathrm{~mm}\right)$.

$\mathrm{x}$ 축 방향 슬롯 길이 $1_{\mathrm{s} 2}$ 의 변화에 따른 입력 VSWR의 변화는 Fig. 3 에 나타나 있다. $x$ 축 방향 슬롯 길이 $1_{\mathrm{s} 2}$ 가
증가할수록 저지 대역의 가장 낮은 주파수와 중심 주파 수가 저주파 대역으로 이동하고 저지 대역의 대역폭도 약간 증가함을 알 수 있다. 그러나 $\mathrm{y}$ 축 방향 슬롯 길이 $1_{\mathrm{s} 1}$ 에 비해서 변화의 폭이 적으므로 큰 영향은 미치지 않음 을 알 수 있다.

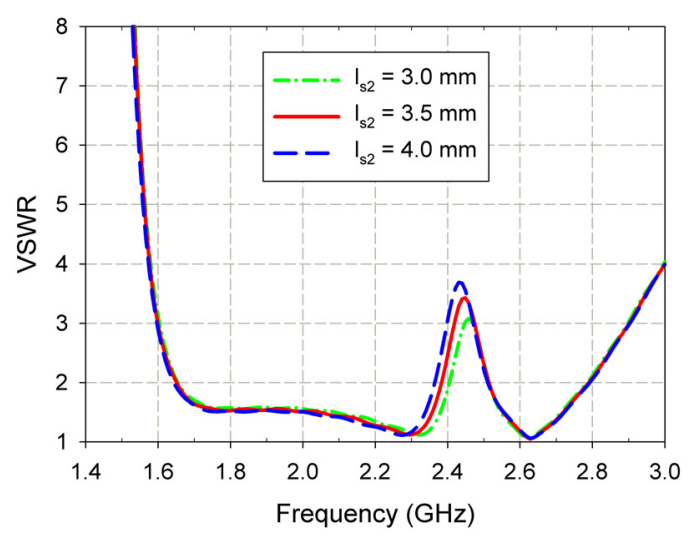

[Fig. 3] Input VSWR characteristic for varying slot length $1_{\mathrm{s} 2}$ in $\mathrm{x}$-direction $\left(\mathrm{l}_{\mathrm{s} 1}=18 \mathrm{~mm}, \mathrm{~g}_{\mathrm{s}}=1.8 \mathrm{~mm}\right.$, and $\left.\mathrm{w}_{\mathrm{us}}=0.5 \mathrm{~mm}\right)$.

Fig. 4는 CPS 선로의 중심부로 부터의 떨어진 거리인 $\mathrm{g}_{\mathrm{s}}$ 의 변화에 따른 입력 VSWR의 변화를 나타내고 있다. $\mathrm{g}_{\mathrm{s}}$ 가 감소될수록 저지 대역의 대역폭과 저지 대역 중심주 파수에서의 VSWR 값이 증가함을 알 수 있다.

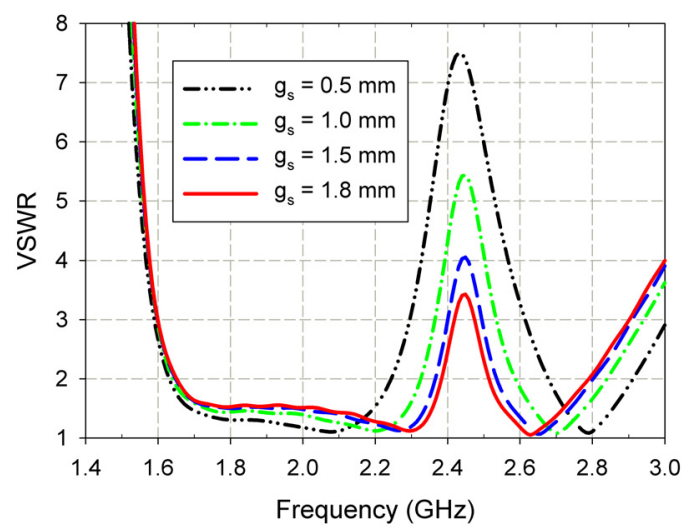

[Fig. 4] Input VSWR characteristic for varying slot location $\mathrm{g}_{\mathrm{s}}\left(1_{\mathrm{s} 1}=18 \mathrm{~mm}, 1_{\mathrm{s} 2}=3.5 \mathrm{~mm}\right.$, and $\left.\mathrm{w}_{\mathrm{us}}=0.5 \mathrm{~mm}\right)$.

슬롯 폭 $\mathrm{w}_{\mathrm{us}}$ 의 변화에 따른 입력 VSWR의 변화는 Fig. 5 에 나타나 있다. $\mathrm{y}$ 축 방향 슬롯 길이 $1_{\mathrm{s} 1}$ 과 $\mathrm{x}$ 축 방향 슬롯 길이 $1_{\mathrm{s} 2}$ 는 고정되어 있고 슬롯 폭이 증가하면 슬롯 안쪽 
으로 커지게 설계하였다. 슬롯 폭 $\mathrm{wus}_{\mathrm{us}}$ 강가할수록 저지 대역의 중심 주파수가 고주파 대역으로 이동하고 저지 대역의 대역폭도 약간 증가하다가 감소함을 알 수 있다. 그러나 $\mathrm{x}$ 축 방향 슬롯 길이 $1_{\mathrm{s} 2}$ 와 마찬가지로 저지 대역 특성에 큰 영향은 미치지 않음을 알 수 있다.

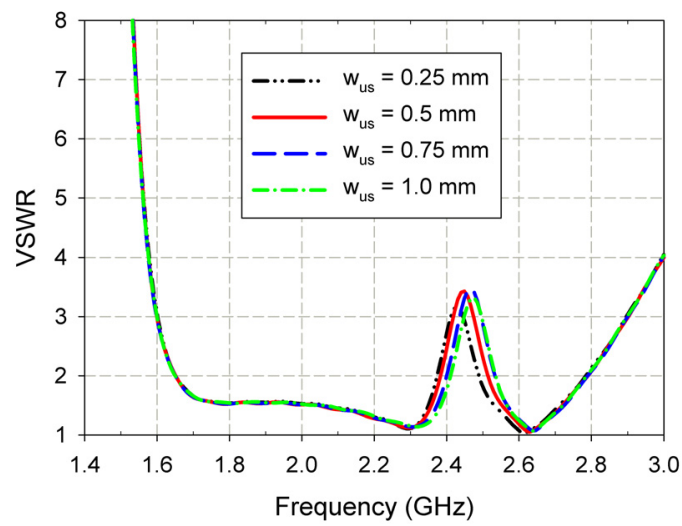

[Fig. 5] Input VSWR characteristic for varying slot width $\mathrm{W}_{\mathrm{us}}\left(1_{\mathrm{s} 1}=18 \mathrm{~mm}, 1_{\mathrm{s} 2}=3.5 \mathrm{~mm}\right.$, and $\left.\mathrm{g}_{\mathrm{s}}=1.8 \mathrm{~mm}\right)$.

\section{3. 제작 및 측정결과}

제안된 설계 방법과 시뮬레이션 결과를 검증하기 위하 여 FR4 기판 $\left(\epsilon_{r}=4.4\right.$, 두께 $=1.6 \mathrm{~mm}$, loss tangent $=$ 0.025)을 이용하여 Fig. 6과 같이 2.4-2.484 GHz WLAN 대역에서 저지 특성을 가지는 SDP 안테나를 제작하였다. 제작된 SDP 안테나의 크기는 $90 \mathrm{~mm} \times 115 \mathrm{~mm}$ 이다.

Fig. 7은 제작된 WLAN 대역 저지 SDP 안테나의 입력 VSWR과 이득 특성을 U자형 슬롯이 없는 SDP 안테나와 비교하고 있다. VSWR < 2인 임피던스 대역폭은 시뮬레 이션 결과 기존의 SDP 안테나와 대역저지 SDP 안테나에 대해서 각각 $47.6 \%(1.68-2.73 \mathrm{GHz})$ 와 $50.5 \%(1.66-2.78$ $\mathrm{GHz})$ 이고, 측정결과는 각각 $48.9 \%(1.70-2.8 \mathrm{GHz})$ 와 $51.0 \%(1.68-2.76 \mathrm{GHz})$ 이다. 시뮬레이션 결과와 측정 결 과가 잘 일치함을 알 수 있으며, 측정결과를 기준으로 대 역 저지 SDP 안테나의 대역폭이 기존 SDP 안테나에 비 해 $2.1 \%$ 증가하였음을 알 수 있다. 저지 대역은 시뮬레이 션 결과와 측정 결과가 각각 $2.38-2.52 \mathrm{GHz}$ 와 2.39-2.54 $\mathrm{GHz}$ 이고 잘 일치함을 알 수 있다. 이득 특성도 시뮬레이 션 결과와 측정 결과가 잘 맞음을 알 수 있다.

이상의 결과들로 볼 때 제안된 $\mathrm{SDP}$ 안테나는 2.4-2.484 GHz WLAN 대역에서 원하는 저지 특성을 갖 는 것으로 볼 수 있다.

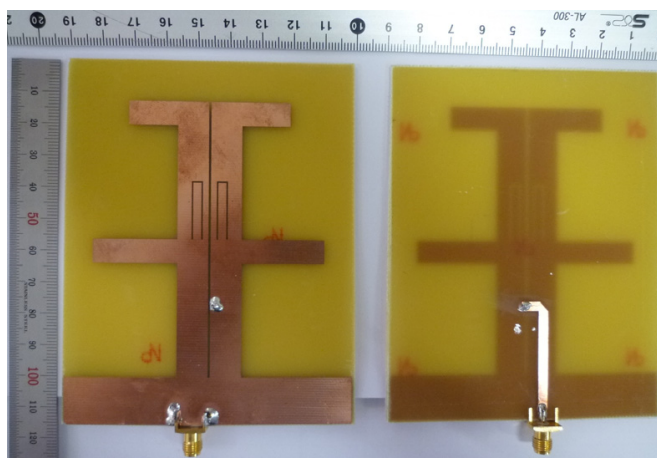

[Fig. 6] Photograph of fabricated SDP antenna with WLAN band rejection characteristic.

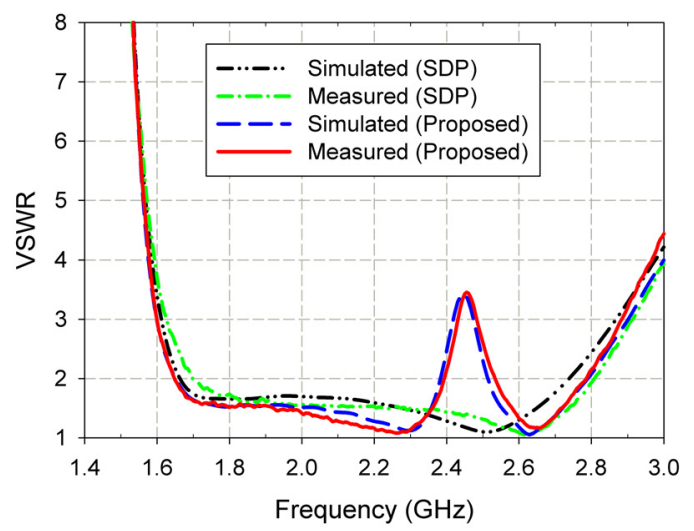

(a)

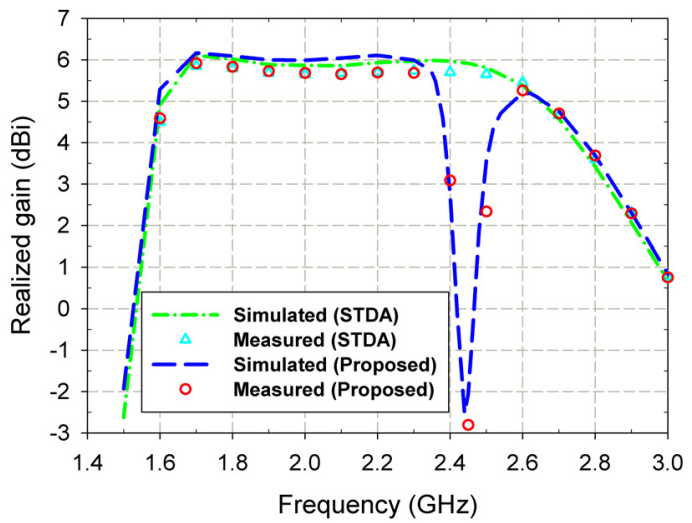

(b)

[Fig. 7] Performance comparison of fabricated SDP antenna with conventional SDP antenna: (a) input VSWR and (b) realized gain.

Fig. 8은 제안된 WLAN 대역 저지 SDP 안테나의 1.8 $\mathrm{GHz}$ 와 $2.45 \mathrm{GHz}$ 에서의 표면 전류분포를 나타내고 있다. $\mathrm{SDP}$ 안테나가 정상적으로 동작하는 주파수인 $1.8 \mathrm{GHz}$ 에 
서는 전류가 두 다이폴에 집중됨을 알 수 있다. 그러나 저지 대역 중심 주파수인 $2.45 \mathrm{GHz}$ 에서는 전류가 $\mathrm{U}$ 자형 슬롯에 집중되고 슬롯이 공진하여 안테나가 동작하지 않 음을 알 수 있다.

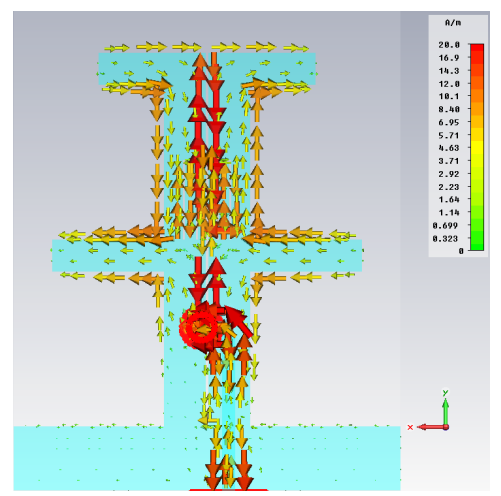

(a)

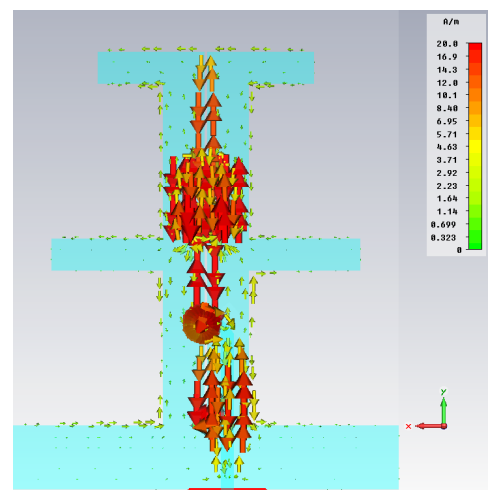

(b)

[Fig. 8] Surface current distribution of proposed SDP antenna with WLAN band rejection characteristic: (a) $1.8 \mathrm{GHz}$ and (c) $2.45 \mathrm{GHz}$.

\section{4. 결론}

본 논문에서는 $1.7-2.7 \mathrm{GHz}$ 대역에서 동작하는 이동통 신 기지국용 광대역 직렬 급전 다이폴 쌍 (SDP) 안테나 에 대하여 2.4-2.484 GHz WLAN 대역에서 저지 특성을 가지기 위한 설계 방법을 연구하였다. 대역 저지 특성은 $\mathrm{SDP}$ 안테나의 두 다이폴 소자를 연결하는 코플래너 스트 립 선로 상에 U자형 슬롯을 삽입함으로써 얻을 수 있다. 슬롯의 위치와 구조에 따른 저지 대역의 특성 변화를 분 석하였다.

최적화된 WLAN 대역 저지 $\mathrm{SDP}$ 안테나를 $\mathrm{FR} 4$ 기판
상에 제작하고 특성을 실험한 결과 VSWR < 2 인 대역은 $1.65-2.78 \mathrm{GHz}(51.0 \%)$ 이고, 저지 대역은 $2.39-2.54 \mathrm{GHz}$ 로 원하는 대역 저지 성능을 갖는 것을 확인하였다.

제안된 안테나는 PCS, IMT2000, LTE 등의 다양한 이 동통신을 지원하는 기지국 안테나 혹은 소출력 중계기용 안테나에 적용하여 대역 내에서 WLAN과 같은 간섭을 방지할 수 있는 대역 저지 특성을 얻기 위해 사용될 수 있을 것으로 기대된다.

\section{References}

[1] R. Waterhouse, Printed Antennas for Wireless Communications. Chichester, U.K.: Wiley, 2007.

[2] R.L. Li, T. Wu, B. Pan, K. Lim, J. Laskar, and M.M. Tentzeris, "Equivalent-circuit analysis of a broadband printed dipole with adjusted integrated balun and an array for base station applications," IEEE Trans. Antennas Propagat., vol. 57, no. 7, pp. 2180-2184, Jul. 2009.

DOI: http://dx.doi.org/10.1109/TAP.2009.2021967

[3] F. Tefiku and C.A. Grimes, "Design of broad-band and dual-band antennas comprised of series-fed printed-strip dipole pairs," IEEE Trans. Antennas Propagat., vol. 48, no. 6, pp. 895-900, Jun. 2000.

DOI: http://dx.doi.org/10.1109/8.865221

[4] A. A. Eldek, "Design of double dipole antenna with enhanced usable bandwidth for wideband phased array applications," Prog. Electromagn. Res., vol. 59, pp. 1 15, 2006

DOI: http://dx.doi.org/10.2528/PIER06012001

[5] N. Kaneda, W.R. Deal, Y. Qian, R. Waterhouse, and T. Itoh, "A broad-band planar quasi-Yagi antenna," IEEE Trans. Antennas Propagat., vol. 50, no. 8, pp. 1158-1160, Aug. 2002.

DOI: http://dx.doi.org/10.1109/TAP.2002.801299

[6] J. Ding, Z. Lin, and Z. Ying, "A compact ultra-wideband slot antenna with multiple notch frequency bands," Microwave. Opt. Technol. Lett., vol. 49, pp. 3056 3060, Sep. 2007.

DOI: http://dx.doi.org/10.1002/mop.22842

[7] J. Liu, S. Gong, Y. Xu, X. Zhang, C. Feng, and N. Qi, "Compact printed ultra-wideband monopole antenna with dual band-notched characteristics," Electron. Lett., vol. 44, pp. 1106 - 1107, Jun. 2008.

DOI: http://dx.doi.org/10.1049/el:20081548

[8] D.O. Kim, N.I. Jo, H.A. Jang, and C.Y. Kim, "Design 
of the ultrawideband antenna with a quadruple-band rejection characteristics using a combination of the complementary split ring resonators," Prog. Electromagn. Res., vol. 112, pp. 93-107, 2011.

[9] W. Wang, S. Gong, Z. Cui, J. Liu, and J. Ling, "Dual band-notched ultra-wideband antenna with codirectional SRR", Microwave Opt. Technol. Lett., vol. 51, pp. 1032-1034, Apr. 2009.

DOI: http://dx.doi.org/10.1002/mop.24255

[10] J. Yeo, and J.-I. Lee, "Broadband series-fed two dipole array antenna with an integrated balun for mobile communication applications," Microw. Opt. Technol. Lett., vol. 54, no. 9, pp. 2166-2168, Sep. 2012. DOI: http://dx.doi.org/10.1002/mop.27009

\section{여 준 호(Junho Yeo)}

[정회원]

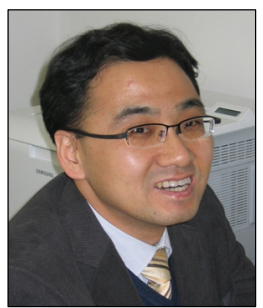

1992년 2월 : 경북대학교 전자공 학과 (공학사)

- 1994년 2월 : 경북대학교 전자공 학과 (공학석사)

- 2003년 8월 : 미국 Pennsylvania State University 전기공학과 (공 학박사)

- 1994년 3월 1999년 6월 : 국 방과학연구소 연구원

- 2003년 9월 2004년 6월 : 미국 Pennsylvania State University 박사 후 과정

- 2004년 8월 2007년 2월 : 한국전자통신연구원 RFID 시스템연구팀 선임연구원

- 2007년 3월 현재 : 대구대학교 정보통신공학부 부교수

<관심분야>

$\mathrm{AMC}, \mathrm{EBG}, \mathrm{FSS}$ 설계 및 안테나 응용,

RFID 및 광대역 안테나, 전자파 산란
홍 재 표(Jae Pyo Hong)

[정회원]

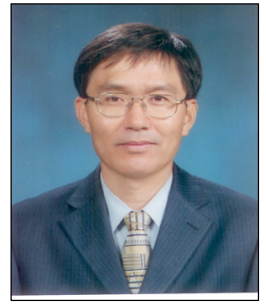

- 1981년 2월 : 경북대학교 전자공 학과 (공학사)

- 1983년 2월 : 경북대학교 전자공 학과 (공학석사)

- 1989년 2월 : 경북대학교 전자공 학과 (공학박사)

- 1990년 2월 현재 : 경일대학 교 전자공학과 교수

<관심분야>

마이크로파 소자 설계, 안테나 설계

\section{이 종 익(Jong-Ig Lee)}

[정회원]

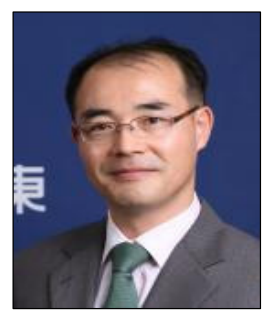

- 1992년 2월 : 경북대학교 전자공 학과 (공학사)

- 1994년 2월 : 경북대학교 전자공 학과 (공학석사)

- 1998년 8월 : 경북대학교 전자공 학과 (공학박사)

- 1998년 3월 12월 : 금오공과 대학교 연구교수

- 1999년 3월 현재 : 동서대학교 전자공학과 교수

<관심분야>

전자파 산란, 평면 안테나 